\title{
Educação Financeira e o Desenvolvimento Sustentável: uma Revisão Sistemática de Literatura
}

\section{Financial Education and Sustainable Development: a Systematic Literature Review}

\author{
Ronaldo Leffler ${ }^{\mathrm{a}}$; Carolina Veiga Ferreira de Souza ${ }^{\mathrm{b}}$; Maria Alice Veiga Ferreira de Souza*a
}

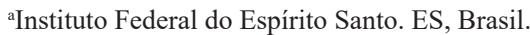 \\ ${ }^{b}$ Universidade Federal Fluminense. RJ, Brasil. \\ *E-mail: mariaalice@ifes.edu.br
}

\begin{abstract}
Resumo
Reconhecida e estimulada mundialmente como política de inclusão e cidadania, a educação financeira vem sendo impulsionada e promovida por instituições financeiras, a exemplo da Estratégia Nacional de Educação Financeira, no caso brasileiro, com objetivos desalinhados e desarticulados com uma proposta escolar que considere a sustentabilidade. Verificamos como investigadores da Educação entendem, definem ou concebem as contribuições da educação financeira nos três pilares do desenvolvimento sustentável - econômico, social e ambiental, defendidos por pesquisadores como D'Ambrosio, Sachs e Dowbor. A importância do tema e de sua implementação nos levaram à uma pesquisa bibliográfica sobre propostas de educação financeira. A investigação foi levada a efeito por meio de uma revisão sistemática de literatura nas bases SCOPUS, Web of Science e ERIC do portal de periódicos da Capes, a partir de 2015, ano do estabelecimento dos Objetivos de Desenvolvimento Sustentável (ODS) pela Organização das Nações Unidas. Foram identificados dois artigos voltados para o pilar econômico, um para o social e um para o ambiental. A educação financeira vem sendo principalmente promovida por organismos internacionais, governos e sistemas financeiros com potencial de promover o desenvolvimento e a estabilidade financeira, aumento de poupança, fortalecimento do sistema previdenciário e sistema financeiro nacional. Ela é percebida como um meio para a redução das desigualdades sociais e transferência de responsabilidades do Estado para os indivíduos. Apesar de sua importância, a discussão no meio científico sobre o papel da educação financeira para promoção do desenvolvimento sustentável, ainda é tímida e incipiente, sobretudo na preservação ambiental.
\end{abstract}

Palavras-chave: Educação Financeira. Desenvolvimento Econômico, Social e Ambiental. Desenvolvimento Sustentável. Desenvolvimento Pleno.

\begin{abstract}
Recognized and encouraged worldwide as a policy of inclusion and citizenship, financial education has been driven and promoted by financial institutions, such as the National Strategy for Financial Education, in the case of Brazil, with objectives that are out of alignment and are not articulated with a school proposal that considers sustainability. We verify how Education researchers understand, define, or conceive the contributions of financial education in the three pillars of sustainable development - economic, social, and environmental, defended by researchers such as D'Ambrosio, Sachs, and Dowbor. The importance of the theme and its implementation led us to bibliographical research on financial education proposals. The investigation was carried out through a systematic literature review in the SCOPUS, Web of Science, and ERIC databases of the Capes journal portal, from 2015 on, the year in which United Nations established the Sustainable Development Goals (SDG). We identified two papers focused on the economic pillar, one on the social and one on the environmental. Financial education has been mainly promoted by international organizations, governments, and financial systems with the potential to promote development and financial stability, increase savings, strengthen the social security system and the national financial system. It is perceived as a means to reduce social inequalities and transfer responsibilities from the State to individuals. Despite its importance, the discussion in the scientific community about the role of financial education in promoting sustainable development is still timid and incipient, especially in terms of environmental preservation.
\end{abstract}

Keywords: Financial Education. Economic, Social, and Environmental Development. Sustainable Development. Full Development.

\section{Contexto para a Investigação}

No mundo contemporâneo impõe-se cada vez mais a importância do fortalecimento de uma educação integral, inclusiva e formativa (Antunes \& Padilha, 2010; D’Ambrosio, 2012), com potencial para preparar os indivíduos para enfrentamento de desafios que emergem da sociedade. Entre esses desafios, devemos considerar o trato com questões financeiras e, portanto, ter em conta uma educação financeira, que é definida pela Organisation for Economic Cooperation and Development (OECD) como:

O processo pelo qual consumidores/investidores financeiros melhoram sua compreensão de produtos, conceitos e riscos financeiros e, por meio de informações, instruções e/ ou conselhos objetivos, desenvolvem habilidades e confiança para se tornarem mais conscientes dos riscos e oportunidades financeiros, para fazer escolhas informadas, para saber onde procurar ajuda e tomar outras ações eficazes para melhorar seu bem-estar financeiro. (OECD, 2005, p.17, tradução livre).

A concepção da OECD inspirou países - a exemplo do Brasil - a desenvolverem ações voltadas para uma educação 
financeira. O Brasil, mesmo que tardiamente quando comparado a países europeus, ao Japão e aos Estados Unidos, veio atender às recomendações da OECD sobre a emergência do desenvolvimento de políticas públicas de promoção de educação financeira no ambiente escolar estabelecendo, pelo decreto 7.397 de dezembro de 2010, a Estratégia Nacional de Educação Financeira (ENEF). A ENEF surgiu como resposta ao impulso das políticas públicas de inclusão social, ao fortalecimento da cidadania, à difusão de noções sobre previdência e ao sistema financeiro nacional (Brasil, 2011). Seu objetivo é auxiliar o cidadão brasileiro a tomar decisões conscientes sobre crédito, proteção, investimento, consumo e planejamento que proporcionem uma vida financeira sustentável que gere impactos positivos, não só na vida individual, mas também na social e, consequentemente, instigue desdobramentos no futuro do país.

Nesse sentido, a ENEF visa à ampliação da compreensão e da tomada de decisão em termos financeiros, podendo ser uma estratégia capaz de promover conhecimentos voltados para o desenvolvimento de uma relação equilibrada das pessoas com o dinheiro. A iniciativa de criação da ENEF colocou o Brasil em uma condição de destaque no mundo, por ser um dos poucos países a instituir uma estratégia nacional de educação financeira gratuita, e teoricamente sem interesses comerciais, estabelecida pela articulação entre 11 instituições de governo e da sociedade civil.

$\mathrm{Na}$ esteira da OECD, o Brasil adotou o conceito de educação financeira daquela organização quase que integralmente, apenas substituindo os termos "consumidores" (ou "investidores") por "indivíduos" e "sociedades". Além disso, a ENEF atribuiu um caráter mais ativo ao acrescentar o termo "formação" no conceito. Apesar do pioneirismo da OECD e das providências tomadas pelo Brasil e outros países, o conceito do que seja ser educado financeiramente ainda está em construção, a exemplo do que vem sendo veiculado em pesquisas científicas, ou talvez pelos lastros de uma visão econômica desenvolvimentista, consumidora e individualista centrada prioritariamente no dinheiro. Em nossa opinião, e ao lado de investigadores científicos (Antunes \& Padilha, 2010; Bauman, 2008; Boff, 2016; Castro, 1984; D’Ambrósio, 2012; Dowbor, 2017; Morin \& Kern, 2003; Sachs, 1993, 2002, 2010, 2015; Santos, 2000; Sen, 1999, 2000, 2001, 2011), esse conceito deve também considerar aspectos ligados aos três pilares do desenvolvimento sustentável - ambiente, sociedade e economia, cuja definição foi dada pela Organização das Nações Unidas (ONU).

A ONU ${ }^{1}$, preocupada com a extrapolação da capacidade de resiliência do meio ambiente devido à exploração exagerada dos recursos naturais por países industrializados, definiu na década de 1980 o desenvolvimento sustentável como aquele "que atenda às necessidades do presente sem comprometer a capacidade das gerações futuras de satisfazer às suas próprias necessidades" (United Nations, 1987, p.24, tradução livre).

É nesse sentido que, a partir do contexto trazido pela OECD e seguido pelo Brasil, por exemplo, apresentamos resultados de um estudo bibliográfico e descritivo (Bogdan \& Biklen, 1994; Gil, 2002; Triviños, 1987) concretizado por meio de uma revisão sistemática de literatura sobre como a comunidade científica mundial da Educação entende, define ou concebe a educação financeira e suas contribuições para o meio escolar, nos três pilares do desenvolvimento sustentável - (1) econômico, (2) social e (3) ambiental.

Em outras palavras, esta revisão sistemática de literatura intenta verificar como a educação financeira vem sendo concebida e aplicada nas escolas, visando ao estímulo de uma reflexão sobre a relevância e urgência de uma educação financeira mais integral e inclusiva ao considerar, por exemplo, questões sociais e ambientais que vão além de uma visão fragmentada, reducionista e insustentável, fundamentada exclusivamente no desenvolvimento econômico, consumo e concentração de renda, denunciada por autores que inauguram a próxima seção deste trabalho.

\section{Literatura Relevante}

A revisão de literatura realizada por Stambassi e Silva (2015) identificou poucos programas voltados para formação de professores em educação financeira escolar no Brasil. Destes poucos, a maioria apresentou foco no planejamento das finanças pessoais, cujo objetivo era o desenvolvimento de uma cultura de poupança, aumento de patrimônio, promoção do equilíbrio e da sustentabilidade financeira, visando à redução do endividamento e da inadimplência junto ao mercado financeiro e comercial. Esses autores concluíram que, na verdade, a finalidade principal daqueles programas era a de informar sobre produtos e serviços do mercado financeiro com o fim de resguardar consumidores de endividamentos e inadimplências pessoais.

O teor desses programas pode ser justificado pelas origens e encaminhamentos da estratégia consubstanciada na ENEF, cujo documento de implantação (Banco Central do Brasil, 2012) informa que, nos anos de 2006 e 2007, sua inteligência foi liderada por quatro órgãos reguladores do sistema financeiro brasileiro ${ }^{2}$ preocupados em:

i) promover e fomentar uma cultura de educação financeira no país; ii) ampliar a compreensão dos cidadãos para que possam fazer escolhas bem informadas sobre a gestão de seus recursos; iii) contribuir para a eficiência e solidez dos mercados financeiro, de capitais, de seguros e de fundos de previdência. (Banco Central do Brasil, 2012, p.11).

\footnotetext{
1 Divulgado em Report of the World Commission on Environment and Development- "our common future".

2 Os quatro órgãos reguladores do sistema financeiro brasileiro: Banco Central do Brasil (BCB), Comissão de Valores Mobiliários (CVM), Superintendência Nacional de Previdência Complementar (PREVIC) e Superintendência de Seguros Privados (SUSEP) (Banco Central do Brasil, 2012).
} 
A citação do Banco Central do Brasil leva a crer que a ENEF está a serviço de uma educação financeira voltada prioritariamente (ou exclusivamente) para o mercado financeiro ao ter sido sugerida pelo Banco Mundial, estimulada pela OECD e liderada por órgãos do sistema financeiro, culminando em um plano de governo seguido pelos programas de formação de professores.

A despeito da importância de uma educação financeira que leve indivíduos à gerência otimizada de seus recursos financeiros, a definição apresentada pela ENEF pode ensejar uma limitação que desconsidere aspectos tão relevantes quanto o mercado financeiro:

[...] o processo mediante o qual os indivíduos e as sociedades melhoram sua compreensão dos conceitos e dos produtos financeiros, de maneira que, com informação, formação e orientação claras, adquiram os valores e as competências necessários para se tornarem conscientes das oportunidades e dos riscos neles envolvidos e, então, façam escolhas bem informados, saibam onde procurar ajuda, adotem outras ações que melhorem o seu bem-estar, contribuindo, assim, de modo consistente para formação de indivíduos e sociedades responsáveis, comprometidos com o futuro. (Banco Central do Brasil, 2012, p.3).

A suspeita da limitação da definição de educação financeira voltada apenas para o mercado de consumo aumenta com a criação de um curso de formação de professores a ser ministrado por uma instituição bancária (Stambassi \& Silva, 2015) e, portanto, desligada de problemáticas ambientais e sociais, por exemplo. Nesse sentido, há carência de articulação com agências e instituições educacionais que tragam ao primeiro plano uma educação que extrapole a dimensão econômica.

Concordamos com Silva e Powell (2015) quando afirmam que os países devem ter em conta uma educação financeira alinhada com suas realidades, e que as instituições de ensino estejam envolvidas nesse processo de construção de currículo e de aulas, por serem esses profissionais preparados para lidar com a formação de estudantes em ambiente escolar. Para além das considerações de Silva e Powell (2015), acrescentamos a importância de inclusão de dimensões que transcendam as particularidades nacionais por se tratarem de pautas mundiais, como a sustentabilidade ambiental. Assim, há que se juntar ao grupo profissionais de ensino e organismos internacionais que tratem dessas novas vertentes em uma abordagem holística, interdisciplinar e sinérgica entre pesquisadores das diversas áreas das Ciências no aproveitamento, conservação e respeito pelos recursos naturais (Sachs, 2002).

Mas, em que perspectiva, a educação financeira pode ser considerada divergente ao desenvolvimento sustentável? Sim, quando essa educação prioriza ou singulariza o eixo econômico (Dowbor, 2017) ou ambiental (apesar de a ênfase histórica estar no eixo econômico), pois, na verdade, o fim deve ser o desenvolvimento social (Sen, 1999, 2000, 2001,
2011) tendo como meios os desenvolvimentos econômico e ambiental. Em outras palavras, a educação financeira converge para o desenvolvimento sustentável somente quando o desenvolvimento social é estabelecido como fim, e os demais pilares como meios voltados ao atendimento das necessidades de toda a sociedade atual e ao resguardo do direito das futuras gerações ao atendimento igual ou superior da satisfação de suas necessidades.

Essas inquietações encontram sintonia em D'Ambrosio (2012, p.9-10) ao afirmar que "só faz sentido insistirmos em Educação se for possível conseguir, por meio dela, um desenvolvimento pleno", ou seja, para além da dimensão dos setores produtivo, comercial e financeiro, uma educação que considere a qualidade de vida, a dignidade do ser humano e as relações dos indivíduos com o meio ambiente. O meio ambiente deve ser incluído nessa educação financeira mais ampla, pois por meio do sistema atual de produção e consumo (Bauman, 2008), os recursos naturais do planeta estão sendo explorados e exauridos em benefício de uma minoria (Sachs, 1993, 2002, 2010, 2015): 7\% da população mundial mais rica são responsáveis por $50 \%$ das emissões de gases de efeito estufa, enquanto $50 \%$ da população mais pobre respondem por $7 \%$ dessas emissões. Seriam necessários cinco planetas para sustentar a humanidade ao padrão atual de consumo per capita do estadunidense (Boff, 2016). "A motivação do lucro a curto prazo age tanto contra a sustentabilidade como contra o desenvolvimento inclusivo" (Dowbor, 2017, p.31). Do mesmo modo pensa $\operatorname{Sen}^{3}$ (1999, 2000, 2001, 2011) - economista internacionalmente reconhecido - ao ser contrário à política dominante de que desenvolvimento e riqueza sejam os fins, considerando-os apenas meios para a melhoria da qualidade de vida e da dignidade humana preconizadas também por D'Ambrosio (2012).

Diante desse contexto, e ao lado de autores, docentes e investigadores científicos que defendem a inclusão social e a preservação ambiental (Antunes \& Padilha, 2010; Bauman, 2008; Boff, 2016; Castro, 1984; D’Ambrósio, 2012; Dowbor, 2017, Morin \& Kern, 2003; Sachs, 1993, 2002, 2010, 2015; Santos, 2000; Sen, 1999, 2000, 2001, 2011); entendemos a necessidade de uma educação financeira comprometida com o desenvolvimento sustentável - o desenvolvimento pleno, nas palavras de D'Ambrosio (2012), que esteja voltado para a responsabilidade social e ambiental, para além da dimensão econômica, como meios de inclusão social e promoção da melhoria da qualidade de vida e dignidade da sociedade humana.

Nesse esteio, baseados na literatura supracitada, identificamos que os temas de desenvolvimento sustentável não devam estar circunscritos somente a algumas áreas do conhecimento, mas devam contar, de modo mais integrado e

3 Amartya Kumar Sen, Economista, Filósofo e ganhador do prêmio Nobel em Ciências Econômicas em 1998, PhD, professor e pesquisador da Harvard University. Foi um dos criadores do Índice de Desenvolvimento Humano (IDH) e consultor para o desenvolvimento humano da Organização das Nações Unidas (ONU) (Leffler, 2019a, 2019b). 
amplo, com contribuições das áreas de Economia, Sociologia, Geografia, Filosofia e Educação, em especial, da Educação Matemática, entre outras. São temas que emergem na atualidade como imperativos para a sobrevivência e a qualidade da vida humana, devendo, portanto, serem promovidos de modo inter, multi e transdisciplinar no meio escolar.

Especificamente, a Educação Matemática é trazida à tona de um contexto educacional maior por conter em sua atenção a Matemática Financeira. Ao falarmos de desenvolvimento sustentável, somos remetidos à importância da Matemática Financeira como meio sine qua non para a promoção (ensino) da educação financeira (Teixeira, 2015). Não uma Matemática Financeira como preconizada por Assaf Neto (2012) e Bruni e Famá (2008, 2013) cujo objetivo principal é o estudo do valor do dinheiro ao longo do tempo. Para além dessa visão reduzida, concebemos os conhecimentos da Matemática Financeira indispensáveis para a promoção da educação financeira por meio do ensino, contribuindo com o tripé da sustentabilidade, de modo a dar sentido ao desenvolvimento educacional que visamos - o desenvolvimento pleno, ou também concebido em nossa visão como desenvolvimento sustentável, que leva em conta questões econômicas, sociais e ambientais.

\section{Método e Procedimentos}

Preocupados com o distanciamento de contribuições emersas da comunidade científica inter, multi e transdisciplinar voltadas para uma educação financeira escolar apoiada no desenvolvimento sustentável defendido pelos autores da literatura científica trazida na seção anterior, propomos uma revisão sistemática de literatura (Caiado et al., 2016), cujo protocolo é apresentado a seguir.

\subsection{Protocolo da revisão sistemática de literatura}

Esta revisão sistemática de literatura está voltada para uma agenda acadêmico-científica denunciada pela comunidade internacional que se manifesta na defesa de uma educação financeira escolar na (para) promoção do desenvolvimento sustentável nos pilares do desenvolvimento econômico, social e ambiental.

Pelas especificidades do desenvolvimento sustentável, cada um dos três objetivos de pesquisa possui descritores próprios em língua inglesa (Tabela 1), política de inclusão e exclusão de trabalhos emersos em cada base de busca, encerrados no mesmo período temporal de publicação.

O estudo foi limitado ao período de 2015-2021 pela ocorrência de um evento promovido pela ONU em 2015, que reuniu líderes de governos para elaboração e aprovação de uma agenda denominada "Transforming our World: The 2030 Agenda for Sustainable Development" (United Nations, 2015) vinculada ao United Nations Development Programme (UNDP), que consiste em 17 objetivos desmembrados em 169 metas para o desenvolvimento sustentável. Esse programa está vigente e objetiva fortalecer a paz universal, a erradicação da pobreza, a inclusão e o cuidado social e a promoção do desenvolvimento sustentável - econômico, social e ambiental (United Nations, 2015). O evento de 2015 parece ter sido um marco inicial em nível mundial, que pretendeu mobilizar diversos países para questões do desenvolvimento sustentável, justificando, assim, nossa opção pelo período deste estudo.

O trabalho foi levado a efeito investigando artigos científicos publicados sob descritores em língua inglesa nas bases Educational Resources Information Center - ERIC, Web of Science - Coleção Principal (Clarivate Analytics) e Scopus (Elsevier) do Portal de Periódicos da Capes. A opção por essas bases não foi aleatória, mas pautada em diferentes razões: A Scopus, por ser a maior base de dados de resumos e citações de literatura revisada por pares (Elsevier, 2016); a Web of Science, por hospedar informações bibliográficas publicadas em periódicos revisados por pares e indexados em diversas áreas do conhecimento (UNICAMP, 2021) e; a ERIC por possibilitar acesso à literatura educacional em mais de mil periódicos indexados e mais de 900 mil publicações revisadas por pares (ProQuest Education, 2020).

$\mathrm{Na} \mathrm{ERIC}^{4}$, a busca foi restrita a artigos completos revisados por pares e restritos à Educação Básica. De início foram localizados quatro artigos relacionados ao primeiro objetivo de pesquisa e nenhum nos outros dois. $\mathrm{Na}$ Web of Science ${ }^{5}$, a procura foi restrita à área da Educação e pesquisa educacional. Foram encontrados três artigos - um para cada objetivo. Na SCOPUS, o rastreio foi restrito à área de Ciências Sociais em artigos de acesso livre em estágio final de publicação. Vale esclarecer que os filtros das bases de dados estão preestabelecidos e diferem entre si. Por essa razão, nossos critérios de busca precisaram de ser realizados segundo as opções impostas pelas bases. Por exemplo, na SCOPUS não existe o filtro "Educação Básica" como consta na ERIC, mas sim, mais amplamente, "Ciências Sociais". Por essa razão, a investigação foi ajustada de modo a atender os objetivos de pesquisa. Foram identificados 16 artigos: 13 referentes ao primeiro objetivo, dois referentes ao segundo e, um referente ao terceiro objetivo - este último encontra-se indisponível no portal de Periódicos da Capes e no Google Scholar e, por esta razão, não será estudado.

A seleção inicial dos 22 artigos seguiu uma política de inclusão e exclusão. Foram incluídos: (1) artigos publicados em periódicos revisados por pares, (2) da área de Educação na ERIC e Web of Science - e da área de Ciências Sociais na SCOPUS. Foram excluídos artigos que apresentaram título, palavras-chave e resumo desconexos com os propósitos desta pesquisa, tais como propostas de sistemas financeiros voltadas para contextos de negócios e que não estavam dirigidos para ambiente da educação escolar. 
Após essa triagem, restaram dez artigos (Quadro 1) que seguiram para avaliação de dois investigadores harmonizados com o tema de investigação visando à avaliação do atendimento aos propósitos desta revisão sob os seguintes questionamentos: (1) O artigo trata educação financeira na educação escolar?; (2) Há coerência com os objetivos de pesquisa [como a educação financeira no meio escolar vem sendo entendida, definida e concebida pela comunidade científica mundial da Educação, e sobre o que tem sido feito para sua promoção]?; (3) Os artigos envolvem ao menos dois descritores de busca?; (4) Os artigos apresentam contribuições da educação financeira para, pelo menos, um pilar do desenvolvimento sustentável [econômico, social, ambiental]?; (5) Os artigos avançam em propostas para além do desenvolvimento econômico?

Quadro 1 - Pergunta, objetivos de pesquisa, bases de busca, descritores, quantidade de artigos emersos e quantidade de artigos incluídos na revisão sistemática de literatura (RSL)

\begin{tabular}{|c|c|c|c|c|c|c|}
\hline \multicolumn{7}{|c|}{$\begin{array}{l}\text { Pergunta: Como a comunidade científica da Educação entende, define ou concebe as contribuições da educação financeira nos três } \\
\text { pilares do desenvolvimento sustentável? }\end{array}$} \\
\hline & Objetivos & Base & Descritores & $\begin{array}{l}\text { Artigos } \\
\text { emersos }\end{array}$ & $\begin{array}{l}\text { Artigos } \\
\text { RSL }\end{array}$ & Selecionados \\
\hline \multirow{3}{*}{11} & \multirow{3}{*}{$\begin{array}{l}\text { Verificar como a comunidade } \\
\text { científica da Educação entende, } \\
\text { define ou concebe as contribuições } \\
\text { da educação financeira escolar para } \\
\text { o desenvolvimento econômico. }\end{array}$} & Scopus & \multirow{3}{*}{$\begin{array}{l}\text { "financial education" AND "economic } \\
\text { development" OR "financial literacy" } \\
\text { AND "economic development" }\end{array}$} & 13 & 6 & \multirow{3}{*}{2} \\
\hline & & $\begin{array}{l}\text { Web of } \\
\text { Science }\end{array}$ & & 1 & - & \\
\hline & & ERIC & & 4 & 2 & \\
\hline \multirow[b]{2}{*}{22} & \multirow[b]{2}{*}{$\begin{array}{l}\text { Verificar como a comunidade } \\
\text { científica da Educação entende, } \\
\text { define ou concebe as contribuições } \\
\text { da educação financeira escolar para } \\
\text { o desenvolvimento social. }\end{array}$} & Scopus & \multirow[b]{2}{*}{$\begin{array}{l}\text { "financial education" AND "social } \\
\text { development" OR "financial literacy" } \\
\text { AND "social development" OR } \\
\text { "financial education" AND "social } \\
\text { responsibility" OR "financial literacy" } \\
\text { AND "social responsibility" }\end{array}$} & 2 & 1 & \multirow[b]{2}{*}{1} \\
\hline & & $\begin{array}{l}\text { Web of } \\
\text { Science }\end{array}$ & & 1 & - & \\
\hline \multirow[t]{2}{*}{33} & $\begin{array}{l}\text { Verificar como a comunidade } \\
\text { científica da Educação entende, } \\
\text { define ou concebe as contribuições } \\
\text { da educação financeira escolar para } \\
\text { o desenvolvimento ambiental. }\end{array}$ & $\begin{array}{l}\text { Web of } \\
\text { Science }\end{array}$ & $\begin{array}{l}\text { "financial education" AND } \\
\text { "sustainability" OR "financial literacy" } \\
\text { AND "sustainability" OR "financial } \\
\text { education" AND "environmental } \\
\text { development" OR "financial literacy" } \\
\text { AND "environmental development" }\end{array}$ & 1 & 1 & 1 \\
\hline & \multicolumn{3}{|r|}{ Total } & 22 & 10 & 4 \\
\hline
\end{tabular}

Fonte: Dados da pesquisa.

Cada questionamento recebeu dos avaliadores um score percentual ( 0 a 100\%), cuja média aritmética igual ou acima de $80 \%$ determinou a inclusão do artigo ao presente estudo. Esta etapa do protocolo resultou em apenas quatro dos 10 artigos (Quadro 1): dois para o objetivo 1, um para o objetivo 2 e um para o objetivo 3 , sobre os quais apresentaremos e discutiremos os resultados a seguir.

\section{Resultados e Discussão}

\subsection{Artigos relativos ao objetivo 1}

Em resposta ao objetivo 1 - Verificar como a comunidade científica da Educação entende, define ou concebe as contribuições da educação financeira escolar para o desenvolvimento econômico - apresentamos o trabalho de Németh, Vargha e Domokos (2020), intitulado "Financial Literacy: Who, whom and what are they training for? Comparative Analysis 2016-2020", cujo objetivo foi apresentar um panorama geral das infraestruturas de treinamento e apoio às finanças públicas húngaras, $e$ avaliar os progressos no desenvolvimento da alfabetização e consciência financeira propiciados por estes programas de formação financeira no país, bem como o envolvimento diante da vulnerabilidade financeira no desenvolvimento de habilidades empreendedoras e estratégias de aposentadoria na Hungria a partir do ano de 2017. Essa ação, promovida pelo governo húngaro, foi estimulada pelo International Monetary Fund (IMF) e pela OECD e levada a efeito por meio de uma estratégia nacional de educação financeira, denominada "Smart with the Money!", que incluiu publicações oficiais de livros didáticos sobre essa temática. A Smart with the Money! pareceu ser algo novo naquele país, vez que até o ano de 2016 o ensino da educação financeira incidia somente em cursos profissionalizantes, sendo optativo para os demais segmentos de ensino.

$\mathrm{Na}$ verdade, o desejo do governo húngaro com a Smart with the Money! era o de alcançar toda sua população e, para isso, envidou esforços, inicialmente, na formação de educação escolar, com estratégias, objetivos, metas e prazos bem definidos e mensuráveis a serem alcançados nas tarefas de confecção, fortalecimento e universalização da educação financeira no sistema público de ensino da Hungria. Os autores não explicitam essa ação educacional ter sido voltada para professores, que ao nosso ver, deveria ter sido iniciada nesse âmbito. A estratégia húngara de educação financeira tinha (ou ainda tem) como meta que as novas gerações se apropriassem de conhecimentos das instituições e processos 
econômicos e financeiros mundiais, nacionais, empresariais e familiares (Németh et al., 2020). Mais especificamente, a Smart with the Money! objetivava promover nos alunos reconhecimento de suas responsabilidades sobre o valor: (1) do trabalho, (2) da gestão racional dos bens, (3) do mundo do dinheiro e (4) do consumo, prevalecendo, ao nosso ver, uma proposta capitalista pouco alinhada com uma educação para o desenvolvimento sustentável.

Essa relação de prioridade no acúmulo de capital pelo indivíduo, família e empresa também pode ser percebida na definição de consciência financeira apresentada pela OECD e incorporada pela estratégia Smart with the Money! ao entenderem a consciência financeira como a habilidade de ampliar, administrar e fazer uso eficiente dos recursos financeiros objetivando contribuir para o bem-estar individual, familiar e empresarial, promovendo segurança econômica (OECD, 2015). Ainda nesse contexto, Németh et al. (2020) reforçam a ideia de que a alfabetização financeira dos indivíduos é fundamental porque influencia direta e indiretamente nos níveis macroeconômicos da política monetária e fiscal, viabilizando os funcionamentos dos mercados e sistema financeiro em sua totalidade, possibilitando o aumento das reservas em poupança do país. Nessa mesma esteira, Németh et al. (2020) apontam diversos pesquisadores (e.g., B. Bernheim, D. Garrett, D. Maki, M. Hilgert, J. Hogarth, S. Beverly, A. Lusardi, O. Mitchell, V. Stango, J. Zinman, M. Van Rooij, R. Alessie) que destacam os benefícios auferidos aos indivíduos pelo estudo da educação financeira, classificando-os como "mais propensos a economizar, planejar a aposentadoria e utilizar menos dinheiro emprestado" (Németh et al., 2020, p.559, tradução livre).

Os resultados da pesquisa de Németh et al. (2020) indicam que 1.310 .352 pessoas foram treinadas em alfabetização financeira entre 2016 e 2019 na Hungria. Desse total, o contingente de 738.470 foram treinadas pela Associação Bancária Húngara e pelo banco Magyar Nemzeti, prevalecendo, portanto, o setor financeiro húngaro como instituição de maior prevalência na disseminação da educação financeira, em detrimento da área educacional daquele país. O público-alvo dos treinamentos, em sua maioria, foram os jovens de 6 a 25 anos de idade, composto predominantemente por alunos da educação pública. Dos 122 programas de treinamento em educação financeira, aproximadamente um sexto foi destinado a grupos que vivem em vulnerabilidade socioeconômica.

Com relação à poupança e previdência, os autores constataram que $74 \%$ dos participantes nos cursos de educação financeira - cerca de 900 mil indivíduos - participaram de temas relacionados às estratégias financeiras para a velhice. Os treinamentos em geral duraram em média cinco dias, de 3 a 4 h diárias. A investigação revelou uma correlação significativa entre o tempo de treinamento e a quantidade de participantes, sinalizando que prazos mais concisos - seja em carga horária diária ou em quantidade de dias - são preferíveis.
Essa correlação deixa de existir quando o público considerado socioeconomicamente vulnerável é remunerado por grupos empresariais no país, pois a ausência do pagamento para essas pessoas inviabiliza a participação nos treinamentos.

O segundo artigo que atendeu ao objetivo 1 deste trabalho foi desenvolvido por Lopus, Amidjono \& Grimes (2019), com título "Improving financial literacy of the poor and vulnerable in Indonesia: An empirical analysis", cujo objetivo foi examinar os resultados de um projeto de educação financeira promovido pela United States Agency for International Development (USAID) na Indonésia. Esse projeto visou melhorar as decisões e habilidades financeiras pessoais de 601 jovens adultos em vulnerabilidade socioeconômica ao longo de 18 meses, entre 2017 e 2018, conduzidos por 25 professores em 30 workshops. Cada treinamento consistiu em 18 seções de 70 minutos sobre noções básicas de alfabetização financeira e habilidades pessoais relacionadas ao emprego. Nesses treinamentos, formadores e alunos foram pré e pós-avaliados com relação à alfabetização financeira e às mudanças na autopercepção e aquisição de habilidades pessoais e sociais para o trabalho.

Os testes aplicados antes e depois da intervenção em educação financeira foram desenvolvidos para o público estadunidense e, por essa razão, sofreram adaptações para a realidade local da Indonésia. Os resultados desses testes evidenciaram que os conhecimentos de alfabetização financeira e a autopercepção de aquisição de habilidades sociais aumentaram significativamente para treinadores e alunos. Os alunos que possuíam experiência de trabalho apresentaram desempenho superior àqueles sem experiência. A maioria dos alunos declarou desejo de implementar os conhecimentos adquiridos de alfabetização financeira em suas vidas. Para Lopus et al. (2019), os resultados emersos do projeto da USAID podem ter implicações positivas para a economia da Indonésia como um todo, para o Sudeste Asiático e para o mundo, no sentido de ampliarem a produtividade, estimularem e darem suporte a práticas de empreendedorismo e empregabilidade, beneficiando alunos, empresas e economias locais.

Para a realização do projeto, a USAID firmou parceria com o Inclusive Workforce Development (IWD) na Indonésia, com objetivo de estimular o desenvolvimento econômico, reduzir as desigualdades de renda e melhorar a empregabilidade dos jovens de 18 a 34 anos. Essa prioridade foi estabelecida conjuntamente com o International Monetary Fund (IMF), a Global Economic Education Alliance (GEEA) e o Indonesian Council on Economics and Financial Education (ICEFE). Para esses organismos, "a alfabetização financeira aumenta potencialmente a confiança e a produtividade do trabalhador, aumenta a empregabilidade e ajuda os trabalhadores a permanecerem empregados, evitando dificuldades financeiras" (Lopus et al., 2019, p.2, tradução livre).

Essas ideias repousam sobre o conceito de educação financeira expresso pela OECD e adotado no currículo 
educacional da Indonésia, incluindo uma combinação de conhecimento, consciência, habilidades, atitudes e comportamentos necessários para tomada de decisões sobre finanças racionais que promovam empregabilidade e segurança financeira pessoal e nacional, tendo em vista que "O bem-estar econômico - independente do grau em que ocorra - está ligado às opções financeiras dos tomadores de decisão e o nível em que essas opções ocorrem é de particular interesse para países em desenvolvimento" (Lopus et al., 2019, p.1, tradução livre).

Em resposta a essas ações educacionais indonésias, a OECD realizou uma pesquisa, e com base nos resultados, confeccionou um documento no qual sugere o fortalecimento de um "sistema de educação profissional mais diversificado e coordenado nacionalmente com alto nível de engajamento patronal" (OECD, 2015, p.20, tradução livre). Assim, o governo indonésio, por meio do Ministério da Educação, buscou aumentar a oferta e a qualidade dos cursos politécnicos voltados para as necessidades locais de desenvolvimento de força de trabalho.

Lopus et al. (2019) entendem que o projeto efetuado pela USAID possui algum respaldo em informações divulgadas pelo World Bank (2018) que diz que mais da metade da força de trabalho na Indonésia são de pessoas que atuam no mercado de modo autônomo, tornando, assim, ainda mais decisivo os vínculos estabelecidos entre alfabetização financeira e o sucesso empresarial.

As investigações de Németh et al. (2020) e de Lopus et al. (2019) versam sobre as estratégias nacionais de educação financeira na Hungria e Indonésia, respectivamente, ambas desenvolvidas no ano de 2017. Essas estratégias foram estimuladas e influenciadas sobretudo pela OECD, sendo de responsabilidade e competência dos ministérios da Fazenda e Economia daqueles países. Os objetivos dessas estratégias visavam, sobretudo, à redução da vulnerabilidade econômica da população, exposta a partir da grande crise financeira de 2008, cujos agentes promotores constituíram-se, principalmente, pelos bancos centrais, instituições financeiras públicas e privadas desses países. Nessa esteira, a educação escolar passou a ser percebida como instrumento para promoção da educação financeira em massa, na preparação de mão de obra qualificada profissional para o mercado de trabalho, reduzindo o absenteísmo, a baixa produtividade, o desemprego, a vulnerabilidade econômica, aliviando a pressão sobre o Estado por programas sociais e previdenciários. Em nenhum desses dois trabalhos foi mencionada a formação de professores como educadores financeiros. O ensino, nesses casos, aconteceu somente a partir do ensino médio profissionalizante, tendo instrutores financeiros como responsáveis pelo desenvolvimento de habilidades em como ganhar, acumular e gerir recursos financeiros, estimular o empreendedorismo e a empregabilidade de jovens e adultos. Em suma, esse contexto nos indica que a educação financeira naqueles países não contemplou o desenvolvimento pleno, tal como definimos neste trabalho, cujo elemento social inaugura o próximo tópico.

\subsection{Artigo relativo ao objetivo 2}

A investigação de Santos (2016), com título "Cultivating the self-reliant and responsible individual: the material culture of financial literacy", analisou algumas propostas internacionais (International Monetary Fund, Organisation for Economic Co-operation and Development, European Commission) e nacionais (governos e reguladores financeiros) de promoção de educação financeira que se pautam sob a ótica de um projeto neoliberal que visa ampliar a mercantilização, reconstruindo a reprodução social e econômica de modo a favorecer o setor financeiro e de consumo. O exame de Santos (2016) resultou na identificação de contradições da política de educação financeira e na constatação de que a melhoria do bem-estar financeiro individual e familiar não são os únicos objetivos daquelas propostas, cujo contexto passamos a detalhar.

Desde 2002 vem sendo disseminada em todo o mundo uma agenda pública global liderada pelo IMF e OECD e outras agências econômicas internas e externas aos países para promoção da educação financeira. Em 2015 essa agenda já integrava a política desenvolvimentista de mais de 240 instituições públicas pulverizadas em mais de 110 países, cujo escopo foi justificado pela necessidade de transferência de responsabilidade do Estado para indivíduos e famílias sobre segurança financeira, por meio da ampliação do mercado e de produtos financeiros destinados a complementar ou substituir a prestação e o investimento público na área de pensões, aposentadoria, seguro saúde, educação, moradia e consumo geral.

A transferência de responsabilidade foi, principalmente, impulsionada pela crise financeira de 2008-2009, sendo estrategicamente utilizada pelo Estado como meio de convencimento para as famílias "se tornarem mais preocupadas e interessadas em questões financeiras" (OECD, 2009, p.78, tradução livre) e, consequentemente, consolidando ações que tornariam a alfabetização financeira uma habilidade de vida mais relevante e necessária ao convívio harmonioso do indivíduo nesse mercado global "financeirizado" e turbulento.

Antes mesmo da crise de 2008-2009, Santos (2016) destaca que a European Commission (2007, p.4), já se mostrava atenta às questões ligadas à educação financeira de sua população. Nas palavras da Comissão:

A educação financeira pode ajudar as crianças a entender o valor do dinheiro e ensiná-las sobre orçamento e economia. Pode dar aos alunos e jovens habilidades importantes para a vida independente, por exemplo, na gestão e pagamento de empréstimos estudantis. Ela pode ajudar os adultos no planejamento de grandes eventos, como comprar uma casa ou tornando-se pais. Pode ajudar os cidadãos a fazer uma melhor provisão financeira para situações imprevistas, investir sabiamente e economizar para sua aposentadoria. (tradução livre). 
Desse contexto, é possível inferir que há entendimento de que a alfabetização financeira deve ser precoce, ou seja, estar presente desde os primeiros anos de vida estudantil, sob pena de incorrer em sérias limitações quando tardiamente ofertada na fase adulta, quando se torna mais difícil a mudança de hábitos e atitudes financeiramente sustentáveis. Essa ideia é reforçada por Santos (2016, citado em OECD, 2013, p.142143), ao declarar que:

A alfabetização financeira torna-se uma condição para a igualdade de oportunidades, como com qualquer outro tipo de alfabetização, atribuindo às escolas a responsabilidade pelo avanço da alfabetização financeira entre todos os grupos demográficos e redução das lacunas e desigualdades na alfabetização financeira. (tradução livre).

Assim sendo, deve ser atribuída ao sistema educacional a responsabilidade da alfabetização financeira para todos (Antunes \& Padilha, 2010; D’Ambrosio, 2012). Nessa direção, o trabalho de Santos (2016) nos remete aos seguintes questionamentos: Estão os professores preparados para assumir essa responsabilidade? A proposta de educação financeira está alinhada aos objetivos educacionais, ou a escola estará a serviço do mercado na promoção do funcionamento e consumo de seus produtos financeiros? Os indivíduos e as famílias assumirão o ônus da responsabilidade previdenciária, reguladora e fiscal na defesa dos direitos do consumidor e riscos do mercado financeiro? Essas reflexões se fazem necessárias na orientação e construção de uma proposta educacional que esteja comprometida com a redução das desigualdades sociais e inclusão dos menos favorecidos e vulneráveis socioeconômicos.

Na visão de Santos (2016), o Estado há muito tempo abandonou seu papel regulador na defesa dos direitos dos menos favorecidos para dedicar-se na promoção do mercado privado e dos sistemas financeiros, transferindo suas responsabilidades coletivas para o indivíduo, não mais visto como um cidadão de direito, mas sim de obrigações. O Estado de direito coletivo agora se torna instrumento de autoridade, suporte e exploração por meio do sistema financeiro. A política, supostamente democrática, criada para defender os interesses do povo, passa a ser submetida aos interesses do mercado, do grande capital, que determina as decisões desde o nível macro até a microeconomia (Bauman, 2008; Boff, 2016; Dowbor, 2017; Santos, 2000). Cada indivíduo está exposto aos riscos do mercado que, além de gozar de plena liberdade para ampliar suas margens de lucro, ainda tem no poder do Estado seu grande financiador e fundo garantidor.

Para Santos (2016), existem contradições nessa proposta mundial de educação financeira. Em primeiro lugar, os indivíduos devem ampliar sua participação como mutuários, investidores e segurados, cabendo ao Estado uma "alfabetização financeira" que promova a responsabilidade e a transferência do ônus dos riscos do mercado financeiro. Em segundo lugar, a proposta da política de educação financeira ainda não está empiricamente fundamentada, apresentando- se com objetivos mais voltados para a venda de produtos financeiros. Em terceiro lugar, a política de educação financeira é agora questionada pelas mesmas fontes que a inspiraram, com resultados de pesquisas indicando que a "baixa capacidade financeira tem mais a ver com psicologia do que com o conhecimento" (De Meza et al., 2008, p.4, tradução livre). Em quarto lugar, a alfabetização financeira não pode ser considerada como uma "capacidade singular que, quando adquirida, afete automaticamente as práticas financeiras das pessoas" (Santos, 2016, p.8, tradução livre), ela não é (e nem pode ser) a única determinante das escolhas dos indivíduos. Em quinto lugar, Santos (2016) diz que vários comentaristas, estudiosos, pesquisadores e profissionais do setor financeiro percebem a educação financeira como algo impossível de ser atingido, dada a velocidade de alteração e lançamento de novos produtos do mercado financeiro, que sempre deixam a educação financeira alguns passos atrás, nunca (ou quase nunca) acompanhando as realidades atuais do mercado. Em sexto lugar, destaca-se a incognoscibilidade intransponível dos riscos inerentes às transações financeiras devidas às inúmeras contingências envolvidas.

Outra evidência das contradições nessa proposta mundial de educação financeira refere-se ao teste First Large-scale International, lançado em 2012, que integrou o Programme for International Student Assessment (PISA), ao buscar avaliar o nível de alfabetização financeira dos jovens com cerca de 15 anos de idade, cujo objetivo declarado é "avaliar até que ponto os jovens estão preparados para os novos sistemas financeiros que estão se tornando mais globais e mais complexos, que devem ser substancialmente diferentes daqueles conhecidos pelas gerações mais antigas" (Santos, 2016, p.3, tradução livre). Essa declaração pode ser resumida em preparar os alunos para o consumo, no enfrentamento dos riscos inerentes aos mais diversificados produtos disponibilizados pelo mercado financeiro.

Santos (2016) ainda questiona a razão da ausência de contestação coletiva da transferência de responsabilidade do Estado para os indivíduos em um momento de níveis degradantes de proteção social, deterioração das leis do trabalho e das condições de vida com o aumento sucessivo do desemprego, endividamento, inadimplência, estagnação e redução da renda e crescentes desigualdades sociais. Santos (2016) dialoga nesse mesmo sentido que Dowbor (2017), Santos (2000) e Sen (1999, 2000, 2001, 2011) sobre as responsabilidades do Estado de garantir o desenvolvimento de políticas públicas inclusivas de segurança protetora, de desenvolvimento humano, de garantia de saúde e educação públicas de qualidade, que levem os benefícios do desenvolvimento econômico a todos, sem, contudo, desconsiderar nossas relações de preservação e respeito com o meio ambiente. Santos (2016, p.10, tradução livre) conclui que “(...) a financeirização promoveu e reforçou formas privadas, mercantilizadas e individualizadas de provisão, que são cada vez mais prejudiciais para pessoas mais vulneráveis 
e com condições cada vez mais deficientes para exercer sua contestação com sucesso".

\subsection{Artigo relativo ao objetivo 3}

Dikmann et al. (2018) pesquisaram o "Professional profile of teachers of Financial Education and Sustainability in the municipal teaching network of Chapecó-SC", com objetivo de identificar o perfil profissional dos professores que atuam com educação financeira e sustentabilidade na rede municipal de ensino de Chapecó-SC, e como são abordados os conteúdos socioambientais em sala de aula, considerando a relação entre a Educação Financeira (vinculada à Matemática) e a Sustentabilidade (vinculada à Educação Ambiental). Os autores justificaram o trabalho pela importância do tema e pela carência de estudos que interrelacionam Educação Matemática e Educação Ambiental.

Para a investigação descritiva e qualitativa, foram selecionadas três escolas da rede municipal de Chapecó-SC, respectivamente pelo critério de menor $(4,5)$, mediano $(6,0)$ e maior $(7,2)$ desempenho no Índice de Desenvolvimento da Educação Básica (IDEB) municipal. Os autores utilizaram documentos, registros escritos e aplicação de questionários aos seis professores da disciplina de Educação Financeira e Sustentabilidade como meio de coleta de dados, cujo tratamento ocorreu por meio de análise de conteúdo - segundo Bardin (2009) - a partir das respostas a três questionamentos: (1) A educação ambiental possibilita uma abordagem interdisciplinar emancipadora e sustentável socioambientalmente? (2) A Matemática, por meio da educação financeira, contribui para o cidadão conhecer e transformar o mundo? (3) A formação permanente de professores na escola voltada para uma práxis pedagógica para a cidadania planetária exige uma dialética interdisciplinar no entendimento do mundo?

Os questionamentos estão pautados no apoio literário que emergiu de uma revisão de literatura que versou sobre a forma como a matemática vem sendo abordada em sala de aula e pela constatação de a educação financeira poder possibilitar e enriquecer esse aprendizado com exemplos práticos do cotidiano propiciando uma forma de olhar transformadora do mundo. Dikmann et al. (2018) concordam com Leite, Ferreira e Scrich (2009) ao esclarecerem que a educação financeira não se limita a um conjunto de ferramentas para cálculos, mas podendo ser meio para planejamento e controle financeiro individual e coletivo que considere a saúde financeira, redução do consumo e desperdício gerando, consequentemente, menor volume de resíduos lançados no meio ambiente. Esse discurso alinha-se ao de Dowbor (2017) quando diz que não podemos ser coniventes com recordes na captura desmedida de pescados a liquidar a vida nos oceanos. Também não podemos aceitar os recordes na produção de alimentos, quando estamos poluindo e liquidando as reservas planetárias de água doce (Dowbor, 2017; Sachs, 2010). Em suma, educar financeiramente não significa para os autores, e para nós, instruir para o acúmulo de riquezas, para o consumismo ou egoísmo, nem somente para refletir sobre a sustentabilidade financeira - como proposta pela OECD -, mas sim, para promover o desenvolvimento econômico, social e ambiental, enfim, o desenvolvimento sustentável em sua plenitude.

Baseados na abordagem Freireana, Dikmann et al. (2018) trouxeram a postura de Reigota (1998, p.9) sobre as questões socioambientais na perspestiva da educação ambiental crítica incluindo a mediação do mundo no processo de ensino e aprendizagem, partindo-se do princípio de que:

O problema ambiental não está na quantidade de pessoas que existem no planeta e que elas precisam consumir cada vez mais os recursos naturais para alimentar, se vestir e ter abrigo. É preciso entender que o problema está no consumo excessivo desses recursos por uma pequena parte da humanidade e no desperdício de artigos inúteis e nocivos à qualidade de vida. (tradução livre).

Dikmann et al. (2018) citam ainda a Carta de Belgrado $(1975)^{6}$ que foi um marco da Educação Ambiental com objetivo de melhorar as relações ecológicas, as relações dos humanos entre si e com a natureza por meio da conscientização, preservação, participação, compromisso, bem-estar e atitudes que devem ser desenvolvidas em uma sociedade sustentável. Enfatizam ainda que a Educação Ambiental apresenta-se como alternativa de sensibilização das pessoas para os cuidados socioambientais na formação de atitudes eco-político-cidadãs e nas mudanças comportamentais insustentáveis degradantes do ambiente de vida.

Igualmente, Dikmann et al. (2018) concordam com Loureiro (2003) ao afirmar que a construção de uma cidadania consistente implica instituir práticas democráticas no cotidiano da escola, de maneira a conduzir o aluno a refletir criticamente em seu ambiente de vida em prol do desenvolvimento de uma cultura para cidadania local, regional e internacional transformadora e sistêmica. Assim, a cidadania não pode ser relegada por nenhuma disciplina escolar, mas que todas as disciplinas contribuam para a mudança cultural em prol do cuidado, respeito, conservação e manutenção dos recursos naturais e existência humana, visando o bem-estar global, mas agindo localmente, percebendo na escola o local ideal dessas realizações. O professor se reveste tal como um maestro dessa grande sinfonia representada pela vida da mãe natureza, da qual todos são beneficiados pelo meio ambiente em que vivem.

Apesar da importância do tema, Kazai e Bredariol (2011), citados por Dikmann et al. (2018), constataram a escassez de projetos, atividades e referenciais teóricos que interrelacionam a Educação Ambiental com a Matemática e, especificamente, em educação financeira, afirmando que:

Quando a Educação Ambiental não é implementada como disciplina, costuma ser utilizada na abordagem de conteúdos de disciplinas como Biologia e Geografia, mais relacionadas

6 A autoria da Carta de Belgrado é da United Nations Environment Programme. 
ao meio físico. Também há esforços pontuais em áreas como História ou Português. Porém, a inserção da Educação Ambiental no contexto da Matemática é extremamente rara. Isso ocorre, eventualmente, em projetos interdisciplinares, entretanto, são poucas as iniciativas para estruturar o processo de ensino da matemática por meio da Educação Ambiental. (Kazai \& Bredariol, 2011, p.227, tradução livre).

Um dos motivos pelos quais poderia justificar essa escassez de material na área de Matemática inter-relacionada à Educação Ambiental se deve provavelmente ao processo de formação dos professores, formados com foco especializado em suas respectivas áreas de pesquisa, sem, contudo, obterem uma visão ampla das problemáticas econômicas, sociais e ambientais inerentes à humanidade (Morin \& Kern, 2003). Investir na formação dos professores como educadores ambientais para que sejam multiplicadores no ambiente escolar pode trazer bons resultados para essa necessária mudança cultural em prol do desenvolvimento sustentável.

Dikmann et al. (2018) apresentam o consumo como tema fundamental relacionando a Matemática e a educação financeira com as questões ambientais. Nesse sentido, afirmamos que o conceito de educação financeira proposto pela OECD não pondera essa relação. Daí surge a necessidade de uma proposta de educação financeira escolar alinhada com as questões socioambientais, com o desenvolvimento sustentável. Consumir é algo inerente a todo ser vivo, entretanto, é primordial refletir sobre a ecologia e até que ponto o consumo humano não compromete a vitalidade $\mathrm{e}$ regeneração dos recursos naturais, colocando em risco a própria existência dos seres vivos (Bauman, 2008; Boff, 2016; Dowbor, 2017; Morin \& Kern, 2003; Sachs, 2010).

O trabalho de Dikmann et al. (2018) nos leva a crer que o consumismo indiscriminado, encarado como fonte inesgotável não contribui para uma educação financeira baseada na sustentabilidade. Além disso, concordam com Fiori e Bernardi (2014) que a matemática oferece potencialidades de promover reflexões sobre o ambiente de vida dos indivíduos para superação da ideologia dominante consumista, superando a ganância do mercado, em uma perspectiva de inclusão e cuidado do ambiente pertencente a todos.

A investigação de Dikmann et al. (2018) revelou dificuldades com relação à formação acadêmica dos professores que lecionam a disciplina de Educação Financeira e Sustentabilidade. De modo geral, os professores pesquisados não possuíam formação específica para lecionar a disciplina. No máximo, dois deles possuíam formação em Ciências Biológicas e desses, havia apenas um com especialização em Matemática. Os autores também identificaram desprovimento de perspectiva na interdisciplinaridade sobre temas da disciplina. Os professores concebiam a disciplina como necessária, mas, se sentiam desamparados pela Secretaria de Educação no que diz respeito à formação profissional específica.

Desafiados por essa realidade, Dikmann et al. (2018) estabeleceram algumas sugestões para qualificar a práxis pedagógica: (1) Formação permanente (contínua) em educação financeira e ambiental para os professores que lecionam a disciplina Educação Financeira e Sustentabilidade; (2) Como ações de médio a longo prazo, sugeriram revisão nas áreas específicas e ambientais na formação inicial de professores que possibilite uma visão ampliada de educação financeira em questões socioambientais e de suas inter-relações na sociedade e na escola e; (3) Revisão econômica no tratamento das questões socioambientais na disciplina pesquisada, em busca de um diálogo de superação da perspectiva exclusivamente conservacionista e preservacionista, para uma visão ampliada e inter-relacionada da educação ambiental com a matemática crítica.

\section{Conclusão}

O presente estudo bibliográfico e descritivo teve como escopo trazer ao primeiro plano entendimentos, definições e concepções da comunidade científica da Educação sobre a educação financeira e suas contribuições para o meio escolar à luz do desenvolvimento sustentável nos pilares econômico, social e ambiental.

Inferimos das pesquisas realizadas na Hungria e Indonésia no ano de 2017, que estes países, inspirados pelo IMF e a OECD, estão elaborando suas estratégias nacionais de educação financeira por meio dos seus ministérios da Fazenda e Economia, bancos centrais e instituições financeiras públicas e privadas, com o objetivo de reduzir a vulnerabilidade econômica da população. Apesar de a educação escolar ser percebida como grande potencial de promoção da educação financeira em larga escala, comprovadamente capaz de propiciar benefícios na qualificação profissional, no aumento da produtividade, na redução do absenteísmo, do desemprego, da vulnerabilidade econômica, ampliação da riqueza pessoal, familiar, empresarial e do país, e sobretudo no alívio da pressão sobre o Estado por programas sociais e previdenciários, em nenhum daqueles países foi apresentado um programa de formação de professores e (ou) de participação de docentes na elaboração de estratégias nacionais de educação financeira.

Sobre o desenvolvimento social, Santos (2016) afirma que desde 2002 o IMF e a OECD vêm disseminando uma agenda global de educação financeira, que além da proposta de melhoria do bem-estar financeiro individual e familiar, redução da pobreza e inclusão social e acesso aos mais variados bens de consumo, visa principalmente a ampliar a mercantilização, reconstruindo a reprodução social e econômica de modo a favorecer o setor financeiro e de consumo, e ainda aliviar a responsabilidade do Estado sobre os serviços sociais, seguros e fundos previdenciários. De fato, ser educado financeiramente amplia as possibilidades de o indivíduo melhorar sua qualidade de vida; entretanto, isso não deve e não pode desobrigar o Estado do seu papel de regulador concernente às suas responsabilidades sociais.

No tocante à preservação do meio ambiente, vimos no trabalho de Dikmann et al. (2018) uma iniciativa interessante 
da Prefeitura Municipal de Chapecó ao introduzir em seu currículo as disciplinas de Educação Financeira e Ambiental, com o objetivo de realizar um trabalho integrado com relação ao consumo, visto aqui por um lado como possibilidade de expansão para aqueles mais favorecidos financeiramente, e por outro, como possibilidades de agressão pela poluição, degradação, desperdício e escassez dos recursos naturais. Portanto, ser educado financeiramente, nessa perspectiva, deve incluir uma proposta de desenvolvimento que contemple a sustentabilidade.

Em todos os artigos pesquisados é reconhecida a importância da educação escolar na formação integral do indivíduo. Todavia, o estudo revelou serem modestos os esforços para orientar professores que atuem com alunos nesse sentido. Concluímos dos estudos que a base para o processo educativo da educação financeira escolar está ancorada na formação de professores e que esse processo carece de maiores investimentos para o desenvolvimento no ambiente escolar, ao lado de investigações que revelem caminhos que culminem em apropriação de conhecimentos específicos nessa vertente.

\section{Agradecimentos}

O presente trabalho foi realizado com apoio da Fundação de Amparo à Pesquisa e Inovação do Espírito Santo (FAPES) ao primeiro autor e da Coordenação de Aperfeiçoamento de Pessoal de Nível Superior (CAPES) à segunda autora, as quais agradecemos.

\section{Referências}

Antunes, A. \& Padilha, P.R. (2010). Educação Cidadã: Educação Integral - fundamentos e práticas (Educação Cidadã 6). Editora e Livraria Instituto Paulo Freire.

Assaf Neto, A. (2012). Matemática Financeira e suas aplicações. São Paulo: Atlas.

Banco Central do Brasil. (2012). Brasil: Implementando a estratégia nacional de educação financeira. Departamento de Educação Financeira. https://www.bcb.gov.br/pre/pef/ port/Estrategia_Nacional_Educacao_Financeira_ENEF.pdf

Bardin, L. (2009). Análise de conteúdo. Lisboa: Edições 70.

Bauman, Z. (2008). Vida para consumo: a transformação das pessoas em mercadorias. São Paulo: Jorge Zahar.

Boff, L. (2016). Sustentabilidade: O que é - O que não é. São Paulo: Vozes.

Bogdan, R. \& Biklen, S. K. (1994). Investigação Qualitativa em Educação: Uma introdução à teoria e aos métodos. Porto: Porto.

Brasil. (2011). Conferências sobre educação financeira acontecerão em maio. Secretaria de Educação Básica. http:// portal.mec.gov.br/component/tags/tag/35996

Bruni, A. L. \& Famá, R. (2008). A Matemática das Finanças. São Paulo: Atlas.

Bruni, A. L. \& Famá, R. (2013). Matemática Financeira: com HP $12 \mathrm{C}$ e Excel. São Paulo: Atlas.

Caiado, R., Rangel, L. A., Quelhas, O. L. G. \& Nascimento, D. (2016). Metodologia de revisão sistemática da literatura com aplicação do método de apoio multicritério à decisão Smarter. Anais do XII Congresso nacional de excelência em gestão em \& III Inovarse - Responsabilidade Social Aplicada. Rio de Janeiro.

Castro, J. (1984). Geografia da fome: o dilema brasileiro: pão ou aço. São Paulo: Antares.

D’Ambrósio, U. (2012). Educação Matemática: da teoria à prática. São Paulo: Papirus.

De Meza, D., Irlenbusch, B. \& Reyniers, D. (2008). Financial Capability: A Behavioural Economics Perspective. London: Financial Services

Dikmann, I., Schlickmann, C.A., Ruppenthal, S. \& Nagorsky, U. (2018). Professional profile of teachers of Financial Education and Sustainability in the municipal teaching network of Chapecó-SC. Tempos e Espaços em Educação, 11(27), 313328. doi: http://dx.doi.org/10.20952/revtee.v11i27.7199

Dowbor, L. (2017). A Era do Capital Improdutivo: Por que oito famílias têm mais riqueza do que a metade da população do mundo? São Paulo: Autonomia Literária.

Elsevier. (2016). Scopus-guia de Referência rápida. https:// www.periodicos.capes.gov.br/images/documents/ Scopus Guia $\% 20$ de $\% 20$ refer $\%$ C $3 \%$ A Ancia $\% 20$ r\%C3\%Ā1pida_10.08.2016.pdf

European Commission. (2007). Communication from the Commission: Financial Education (Brussels: EC). http://eurlex.europa.eu/LexUriServ/LexUriServ. do?uri=COM:2007:0808:FIN:EN:PDF

Fiori, A. F., Bernardi \& L. M. S. (2014). Qual a função sociopolítica da Matemática na educação financeira? Boletim Gepem, 65, 69-79. doi: http://dx.doi.org/10.4322/gepem2015.016

Gil, A. C. (2002). Como elaborar projetos de pesquisa. São Paulo: Atlas.

Kazay, D. F. \& Bredariol, T. O. (2011). A prática da educação ambiental no ensino de Matemática. Revista Eletrônica do Mestrado em Educação Ambiental, 26, 225-242.

Leffler, R. (2019a). Crise Hídrica e Cafeicultura: Impactos, Resiliência e Restrição de Liberdade - O Caso de Jaguarél $E S$. Vitória: Universidade Federal do Espírito Santo.

Leffler, R. (2019b). Educação Financeira: um estudo de caso na formação inicial de professores de matemática. Vitória: Instituto Federal do Espírito Santo.

Leite, M. B. F., Ferreira, D. H. L. \& Scrich, C. R. (2009). Explorando conteúdos matemáticos a partir de temas ambientais. Ciência \& Educação, 15(1), 129-138. doi: http:// dx.doi.org/10.1590/S1516-73132009000100008

Lopus, J. S., Amidjono, D. S. \& Grimes, P. W. (2019). Improving financial literacy of the poor and vulnerable in Indonesia: An empirical analysis. Elsevier, 32. doi: https://doi.org/10.1016/j. iree.2019.100168

Loureiro, C. F. B. (2003). Premissas teóricas para uma educação ambiental transformadora. Revista Ambiente e Educação, 8, 37-54.

Morin, E. \& Kern, A. B. (2003). Terra Pátria. Porto Alegre: Sulina.

Németh, E., Vargha, B. T. \& Domokos, K. (2020). Financial Literacy. Who, whom and what are they Training for? Comparative Analysis 2016-2020. Public Finance Quarterly, 4, doi: https://doi.org/10.35551/PFQ_2020_4_7

OECD.(2005).ImprovingFinancialLiteracy:Analysisofissuesand 
Policies. https://www.oecd.org/finance/financial-education/ improvingfinancialliteracyanalysisofissuesandpolicies.htm

OECD. (2009). Financial Education and the Crisis: Policy Paper and Guidance. OECD Publishing, Paris, France. https://www. oecd.org/finance/financial-education/50264221

OECD. (2013). Advancing national strategies for financial education: A joint publication by Russia's G20 presidency and the OECD. https://www.oecd.org/finance/financialeducation/G20_NSFFinancialEducation.pdf

OECD. (2015). Asian Development Bank - Education in Indonesia: Rising to the Challenge. OECD Publishing, Paris, France. https://doi.org/10.1787/9789264230750-en.

ProQuest Education. (2020). ERIC -Education Resources Information Center. http://www.periodicos.capes.gov.br/ images/documents/ProQuest\%20-\%20ERIC\%20(guia).pdf

Reigota, M. (1998). O que é Educação Ambiental. São Paulo: Brasiliense.

Sachs, I. (1993). Estratégias de transição para o século XXI: desenvolvimento e meio ambiente, Studio Nobel.

Sachs, I. (2002). Caminhos para o desenvolvimento sustentável (P.Y. Stroh, org.). Garamond.

Sachs, I. (2010). Barricadas de ontem, campos de futuro. Estudos Avançados, 24(68), 25-38. https://www.revistas.usp.br/eav/ article/view/10464

Sachs, I. (2015). Entering the Anthropocene: The Twofold Challenge of Climate Change and Poverty Eradication. In F. Mancebo \& I. Sachs (Eds.), Transitions to Sustainability (pp. 7-19). Springer.

Santos, A. C. (2016). Cultivating the self-reliant and responsible individual: the material culture of financial literacy. New Political Economy, doi: 10.1080/13563467.2017.1259302. http://dx.doi.org/10.1080/13563467.2017.1259302

Santos, M. (2000). Por uma outra globalização - do pensamento único à consciência universal. Record.

Sen, A. K. (1999). Sobre ética e economia. Companhia das Letras.

Sen, A. K. (2000). Desenvolvimento como liberdade. Companhia das Letras.
Sen, A. K. (2001). Desigualdade reexaminada. Record.

Sen, A. K. (2011). Ideia de Justiça. Companhia das Letras.

Silva, A. M. \& Powell, A. B. (2015). Educação Financeira na Escola: a perspectiva da organização para cooperação e desenvolvimento econômico. Boletim Gepem, 66(24), pp. $3-19$.

Stambassi, A. \& Silva, A. M. (2015). Um curso de educação financeira escolar para professores que ensinam matemática. Anais do XIX Encontro Brasileiro de Estudantes de PósGraduação em Educação Matemática. Universidade Federal de Juiz de Fora. https://www.ufjf.br/ebrapem2015/anais/ sessao-c-3110-manha/

Teixeira, J. (2015). Um estudo diagnóstico sobre a percepção da relação entre educação financeira e matemática financeira. [Tese de Doutorado em Educação Matemática - Pontifícia Universidade Católica de São Paulo. https://sapientia.pucsp. br/handle/handle/11025

Triviños, A. N. S. (1987). Introdução à Pesquisa em Ciências Sociais: a pesquisa qualitativa em Educação. São Paulo: Atlas.

UNICAMP. (2021). Help Capes Lattes WoS obtendo arquivos do Web of Science. Sistema de informação de ensino, pesquisa e extensão-SIPEx. https://www.unicamp.br/sipex/?page $\mathrm{id}=356$

United Nations Environment Programme. (1975). The Belgrade Charter: a framework for environmental education. https:// unesdoc.unesco.org/ark:/48223/pf0000017772

United Nations. (1987). Report of the World commission on Environment and Development. https://digitallibrary.un.org/ record/139811\#record-files-collapse-header

United Nations. (2015). Transforming our World: The 2030 Agenda for Sustainable Development. A/ RES/70/1. United Nations Development Programme - UNDP. https://sustainabledevelopment.un.org/ content/documents $/ 21252030 \% 20$ Agenda $\% 20$ for $\% 20$ Sustainable\%20Development $\% 20$ web.pdf

World Bank, 2018. Self-employed, Total (\% of Total Employment) (modeled ILO Estimate), Databank. https://data.worldbank. org/indicator/SL.EMP.SELF.ZS 